\title{
EFFECT OF Er,Cr:YSGG LASER VERSUS ACID ETCHING SURFACE TREATMENT ON THE SURFACE ROUGHNESS AND TOPOGRAPHY OF TWO PRESSABLE LITHIUM DISILICATE CERAMICS. "IN-VITRO STUDY"
}

\author{
Mohamed Tarek* $^{*}$ Ihab Msoleh ${ }^{* *}$ and Hanaa Zaghloul ${ }^{* * *}$
}

\begin{abstract}
Objective: To assess the effect of two surface treatment protocols of two pressable lithium disilicate ceramics with different thicknesses on the surface roughness and topography.

Material and methods: Sixty four lithium disilicate ceramic discs were divided into two groups ( $n=32)$; IPS e.max Press and Initial ${ }^{\mathrm{TM}}$ LiSi Press. Each group was subdivided into two subgroups $(n=16)$ according to thicknesses $(0.5 \mathrm{~mm}$ and $1 \mathrm{~mm})$. Each subgroup was divided into two subdivisions $(n=8)$ according to the surface treatment; Er:Cr:YSGG Laser and hydrofluoric acid etching. Artificial aging was performed for all the specimens. Surface roughness (Ra) before and after surface treatment protocol was measured using contact stylus profilometer and their topographical changes were identified using scanning electron microscope.
\end{abstract}

Results: there was no significant difference in Ra values between the two ceramic types before and after surface treatment. There was no significant difference in Ra values between the two surface treatments on both ceramics. There was a difference in the effect of the surface treatments on the topography of the ceramics

Conclusion: Both surface treatments have comparable effect on the surface roughness of lithium disilicate ceramic but have different effect on the ceramic's topography.

KEYWORDS: Er:Cr:YSGG Laser, Lithium Disilicate, Surface roughness, Topography.

\footnotetext{
* Faculty of Oral and Dental Medicine, Misr International University, Cairo, Egypt.

** Faculty of Dentistry (Prosthodontics Department), King Abdulaziz University, Jeddah Saudi Arabia/ Cairo University, Cairo, Egypt.

*** Faculty of Oral and Dental Medicine, Conservative Dentistry Department (Fixed Prosthodontics), Misr International University, Cairo, Egypt.
} 


\section{INTRODUCTION}

The increased demand for high esthetics initiated the development of tooth colored restorative materials with superior esthetics and mechanical properties ${ }^{[1]}$. Lithium disilicate, a glass ceramic, consists of crystalline structures ( $70 \%$ by volume) embedded into a glassy matrix ${ }^{[2]}$.

An effective bonding depends on the micromechanical interlocking between the glass ceramic and the resin cement ${ }^{[3]}$. The surface treatment protocols for dental ceramics enhance the bonding between the restoration and the dental structure through the modification of internal surface of the ceramic by creating micro-porosities and increasing the surface area for bonding. There are several surface treatment protocols for lithium disilicate ceramics including the standard method of hydrofluoric acid etching and laser irradiation ${ }^{[1,4]}$.

The standard method for treating the intaglio surface of glass ceramics is hydrofluoric acid etching ${ }^{[5]}$. Hydrofluoric acid etching selectively removes the glassy matrix of the ceramic exposing the crystalline structures ${ }^{[6]}$. When lithium disilicate ceramic's surface is treated by hydrofluoric acid etchant, the glassy matrix is dissolved and removed showing the elongated crystals of lithium disilicate which creates irregularities, peaks and valleys ${ }^{[7]}$. The hydroflouric acid removes the glassy matrix because the fluoride present in the acid has high affinity to silicon present in the lithium disilicate ceramic $^{[8]}$.

The acid etching of the ceramic surface increases the surface energy of the ceramic surface which enhances the chemical bond between the inorganic matrix of the ceramic and the organic matrix of the resin cement and also increases the micromechanical retention with the resin cement ${ }^{[4,9,10]}$. Hydrofluoric acid etching has a positive effect on the topography of the ceramic's surface ${ }^{[5]}$ as it increases the surface roughness for bonding and enhances or stabilizes the defects on the ceramic surface ${ }^{[11,12]}$. Regarding the mechanical behavior after hydrofluoric acid etching, hydrofluoric acid does not change the flexural strength of lithium disilicate as long as used under the manufacturer's recommendations ${ }^{[12]}$.

Etching time, the concentration of the hydrofluoric acid etchant and the ceramic's type affect the pattern of the etching procedure ${ }^{[4]}$. Increasing the acid etch concentration and/or the etching time above the manufacturer's recommendation can alter the nature of the ceramic. Micro-defects, grooves and cracks can occur at the surface of the lithium disilicate ceramic as a side effect of abusing the hydrofluoric acid etchant. Hydrofluoric acid can weaken the lithium disilicate ceramic if not used properly following the manufacturer's recommendations ${ }^{[10,13-15]}$.

After the first introduction of laser (the Ruby laser) by Maiman in 1960, other kinds of laser like $\mathrm{CO} 2$ and ND:YAG lasers have been produced and used in the dental field ${ }^{[16,17]}$. However, these types of laser have thermal side effects on the hard tissues and dental ceramics such as; melting, cracks, fractures, carbonization and increasing the pulpal temperatures ${ }^{[18],[19]}$, which lead to the introduction of Erbium lasers into the dental market ${ }^{[20,21]}$.

Laser surface treatment works on the ceramic surface through the process of thermo-mechanical ablation through micro-explosion and vaporization of the ceramic material, leading to porcelain ablation as a result of the reaction between the water film on the ceramic surface and the laser beam (water mediated micro-mechanical ablation), leading to the dissolving of the glassy matrix of the ceramics ${ }^{[22,23]}$.

Er,Cr:YSGG laser is a non-invasive, conservative and painless intervention used to cut soft and hard dental tissues ${ }^{[24,25]}$, it also produces surface roughness similar to that produced by acid etching of enamel and dentin ${ }^{[23,26]}$. Er,Cr:YSGG laser has been used as a surface treatment protocol for some ceramics including zirconia but its effect on lithium disilicate ceramic is still controversial ${ }^{[24,25]}$. In addition, there is no standard 
protocol for the ceramic surface treatment with Er,Cr:YSGG laser regarding to the laser parameters used (power output, duration and frequency) ${ }^{[24,26]}$. Hydrofluoric acid has a potential health hazard to the dentists due to its toxicity, hydrofluoric acid can damage the skin or irritates the eyes if it came in contact with them accidentally or hurt the lungs of the dentists on the long run due to its volatility. ${ }^{[27-29]}$ So, the aim of the present study is to assess the effect of two different surface treatment protocols (acid etching and laser irradiation) of two pressable lithium disilicate ceramic materials with different thicknesses on the surface roughness and topography. The first null hypothesis was there will be no difference between the two surface treatment protocols on the surface roughness for each pressable lithium disilicate ceramic. The second null hypothesis was there will be no difference in the surface roughness between the two pressable lithium disilicate ceramics. The third null hypothesis was there will be no difference between the two surface treatment protocols on the surface topography for each pressable lithium disilicate ceramic.

\section{MATERIALS AND METHODS}

Sixty four lithium disilicate ceramic disc specimens were divided into two equal groups according to the ceramic type $(n=32)$ into; IPS e.max Press (Ivoclar Vivadent AG Schaan, Liechtenstein, Germany) (HT A1) and GC Initial ${ }^{\mathrm{TM}}$ LiSi Press (GC Corporation Tokyo, Japan) (HT -E58). Each group was further subdivided into two equal subgroups $(n=16)$ according to their thicknesses $(0.5 \mathrm{~mm}$ and $1 \mathrm{~mm})$. Each subgroup was divided into two equal subdivisions $(n=8)$ according to the surface treatment protocol: Er:Cr:YSGG Laser and Hydrofluoric acid etching.

\section{Samples' preparation}

Sixty-four ceramic disc specimens were fabricated through the lost wax/pressing technique following the manufacturers' instructions. For the wax pattern construction, an STL (Standard Tessellation Language) file of a rod (10 cm length $\mathrm{x} 10 \mathrm{~mm}$ diameter) was designed and sent to the 5-axis Roland DWX-51D (Roland DG, Australia) CAD/CAM milling machine's software for milling the wax rods. Four wax rods were milled out of a CAD/CAM gray $14 \mathrm{~mm}$ KATANA wax Disc (Kuraray Noritake Dental Inc. Japan). To fabricate the wax pattern discs, the wax rods were sliced perpendicularly into discs with $10 \mathrm{~mm}$ diameter and two thicknesses $(0.5 \mathrm{~mm}$ and $1 \mathrm{~mm})$ using Isomet 4000 microsaw (Buehler, USA). Slicing was carried out with a low speed water cooled cutting disk of $0.5 \mathrm{~mm}$ thickness (speed: $2500 \mathrm{rpm}$ with a feeding rate of $10 \mathrm{~mm} / \mathrm{min}$ under water cooling system). Standardization of the disc specimens' dimensions was checked using an electronic digital caliper (Mitutoyo, Japan) to confirm the required thickness.

After investing the wax disc specimens, IPS e.max investment ring system (Ivoclar Vivadent AG Schaan, Liechtenstein, Germany) was placed in Programat EP 3010 furnace (Ivoclar Vivadent AG Schaan, Liechtenstein, Germany) and preheated to $850^{\circ} \mathrm{C}$ following the manufacturer's instructions. Pressing of IPS e.max Press ingots (Ivoclar Vivadent AG Schaan, Liechtenstein, Germany) and GC Initial ${ }^{\mathrm{TM}} \mathrm{LiSi}$ Press ingots (GC Corporation Tokyo, Japan) was carried out in ceramic press furnace Programat EP 3010 (Ivoclar Vivadent AG Schaan, Liechtenstein, Germany) following the manufacturer's instructions: stand-by temperature: $700^{\circ} \mathrm{C}$, heat rate: $60^{\circ} \mathrm{C} / \mathrm{min}$, holding temperature: $910^{\circ} \mathrm{C}$ and holding time: $25 \mathrm{~min}$. After divesting, the ceramic disc specimens' dimensions were checked using an electronic digital caliper (Mitutoyo, Japan). The ceramic discs were coated on one side with IPS classic V Transparent Neutral (Ivoclar Vivadent AG Schaan, Liechtenstein, Germany) and fired in the ceramic furnace Programat EP 3010 (Ivoclar Vivadent AG Schaan, Liechtenstein, Germany) at $765{ }^{\circ} \mathrm{C}$ following the manufacturer's instructions. 
Ultradent ${ }^{\circledR}$ Porcelain Etch 9\% buffered (Ultradent, South Jordan, USA) Hydrofluoric acid etchant was applied on the unglazed surface of the ceramic discs by a brush following the manufacturer's instruction then removed by air/ water spray then dried. ${ }^{[30-33]}$

The laser surface treatment protocol was carried out using Er,Cr:YSGG laser (Waterlase iplus, BIOLASE, Inc. USA) of wavelength $2790 \mathrm{~nm}$ (power setting: 4.5 watt, repetitive rate of $50 \mathrm{~Hz}$ "pulse per second" and pulse duration "pulse length": $60 \mu \mathrm{s}){ }^{[23],[24]}$ with a sweeping motion directing the Waterlase Laser Tip MGG6-9 (BIOLASE, Inc. USA) $45^{\circ}$ angle to the unglazed ceramic surface at a distance of $2 \mathrm{~mm}$ with $80 \%$ water and $60 \%$ air for 60 seconds.

Before and after surface treatment, the ceramic discs were ultrasonically cleaned in a distilled water for 10 minutes then dried with an oil-free air spray.

\section{Surface roughness measurement}

Before and after surface treatment, the surface roughness of the ceramic disc specimens was measured with a contact stylus profilometer [34]-[36] (Elcometer 224/2, Elcometer Instruments, Great Britain) with USB digital surface profile gauge. Data were recorded using computer software of roughness tester while the needle scanning the geometric center of the specimen and two other points. The average of the three measurements was used to obtain the mean Ra value of each specimen.

\section{Scanning electron microscopy (SEM)}

To identify the morphological changes of the surface treatment protocols, four samples of $1 \mathrm{~mm}$ subdivisions were scanned before and after surface treatment by using scanning electron microscope (Model Quanta 250 FEG, FEI Company, Netherlands) attached with EDX Unit. Images of each specimen were taken at magnification of $1500 \mathrm{X}$ and $6000 \mathrm{X}$.

\section{Statistical Analysis}

Numerical data were explored for normality by checking the distribution of data and using tests of normality (Kolmogorov-Smirnov and Shapiro-Wilk tests). Surface roughness (Ra) data showed nonnormal (non-parametric) distribution. Data were presented as mean and standard deviation (SD) values. Mann-Whitney U test was used to compare between the two ceramic types, surface treatments and thicknesses. Wilcoxon signed-rank test was used to compare between $\mathrm{Ra}$ values before and after surface treatment. Bonferroni's post-hoc test was used for pair-wise comparisons when ANOVA test is significant. The significance level was set at $\mathrm{P} \leq 0.05$. Statistical analysis was performed with IBM SPSS Statistics for Windows, Version 23.0. Armonk, NY: IBM Corp.

\section{RESULTS}

\section{Surface roughness analysis}

The means and the standard deviations of the surface roughness values in the two ceramic types, two thicknesses either before or after surface treatment showed no statistically significant difference between mean Ra values of the two surface treatment protocols. (Table 1)

\section{SEM analysis}

Before surface treatment, the SEM images showed that GC Initial ${ }^{\mathrm{TM}}$ LiSi Press showed smaller sized crystals that were multilayered and more densely packed than IPS e.max Press (figures 1a, 1b, 1c \& 1d). Both surface treatment protocol showed that same surface roughness with both ceramics, as they dissolved the glassy matrix but there was difference in surface topography (figures 1e, 1f, 1g, $1 \mathrm{~h}, 1 \mathrm{i}, 1 \mathrm{j}, 1 \mathrm{k} \& \mathrm{1l})$. The laser irradiated ceramic surface showed more surface waviness and showed areas of cracks, defects and striations and increase in the crystalline size (figures $1 \mathrm{i}, 1 \mathrm{j}, 1 \mathrm{k} \& 11$ ). 
TABLE (1) : The mean, standard deviation (SD) values and results of Mann-Whitney U test for comparison between Ra values of the two ceramic types, two surface treatments, two thicknesses and Wilcoxon signed-rank test for comparison between Ra values before and after surface treatment

\begin{tabular}{|c|c|c|c|c|c|c|c|c|}
\hline \multirow{2}{*}{ Time } & \multirow{2}{*}{ Thickness } & \multirow{2}{*}{$\begin{array}{l}\text { Surface } \\
\text { treatment }\end{array}$} & \multicolumn{2}{|c|}{ IPS e.max } & \multicolumn{2}{|c|}{ Initial LiSi } & \multirow{2}{*}{$P$-value } & \multirow{2}{*}{$\begin{array}{l}\text { Effect } \\
\text { size }(d)\end{array}$} \\
\hline & & & Mean & SD & Mean & SD & & \\
\hline \multirow{5}{*}{$\begin{array}{l}\text { Before surface } \\
\text { treatment }\end{array}$} & \multirow{2}{*}{$0.5 \mathrm{~mm}$} & Laser & 0.272 & 0.175 & 0.28 & 0.153 & 0.462 & 0.374 \\
\hline & & HF acid & 0.198 & 0.106 & 0.233 & 0.089 & 0.248 & 0.603 \\
\hline & \multicolumn{2}{|c|}{$\begin{array}{l}P \text {-value, }(\text { Effect size) between } \\
\text { surface treatments }\end{array}$} & \multicolumn{2}{|c|}{$0.270(0.574)$} & \multicolumn{2}{|c|}{$0.600(0.265)$} & & \\
\hline & \multirow{2}{*}{$1 \mathrm{~mm}$} & Laser & 0.313 & 0.139 & 0.234 & 0.115 & 0.172 & 0.726 \\
\hline & & HF acid & 0.367 & 0.146 & 0.189 & 0.101 & $0.027^{*}$ & 1.322 \\
\hline & \multicolumn{2}{|c|}{$\begin{array}{l}P \text {-value, (Effect size) between } \\
\text { surface treatments }\end{array}$} & \multicolumn{2}{|c|}{$0.600(0.265)$} & \multicolumn{2}{|c|}{$0.600(0.265)$} & & \\
\hline \multirow{2}{*}{\multicolumn{2}{|c|}{$\begin{array}{l}P \text {-value, (Effect size) between } \\
\text { thicknesses }\end{array}$}} & Laser & \multicolumn{2}{|c|}{$0.318(0.515)$} & \multicolumn{2}{|c|}{$0.462(0.374)$} & & \\
\hline & & HF acid & \multicolumn{2}{|c|}{$0.016 *(1.515)$} & \multicolumn{2}{|c|}{$0.248(0.603)$} & & \\
\hline \multirow{5}{*}{$\begin{array}{l}\text { After surface } \\
\text { treatment }\end{array}$} & \multirow{2}{*}{$0.5 \mathrm{~mm}$} & Laser & 0.341 & 0.089 & 0.351 & 0.073 & 0.916 & 0.053 \\
\hline & & HF acid & 0.281 & 0.074 & 0.306 & 0.088 & 0.529 & 0.319 \\
\hline & \multicolumn{2}{|c|}{$\begin{array}{l}P \text {-value, }(\text { Effect size) between } \\
\text { surface treatments }\end{array}$} & \multicolumn{2}{|c|}{$0.172(0.726)$} & \multicolumn{2}{|c|}{$0.401(0.430)$} & & \\
\hline & \multirow{2}{*}{$1 \mathrm{~mm}$} & Laser & 0.062 & 0.048 & 0.058 & 0.037 & 0.916 & 0.053 \\
\hline & & HF acid & 0.078 & 0.061 & 0.051 & 0.022 & 0.462 & 0.374 \\
\hline & \multicolumn{2}{|c|}{$\begin{array}{l}P \text {-value, (Effect size) between } \\
\text { surface treatments }\end{array}$} & \multicolumn{2}{|c|}{$0.563(0.292)$} & \multicolumn{2}{|c|}{$0.674(0.211)$} & & \\
\hline
\end{tabular}

*: Significant at $P \leq 0.05$ 

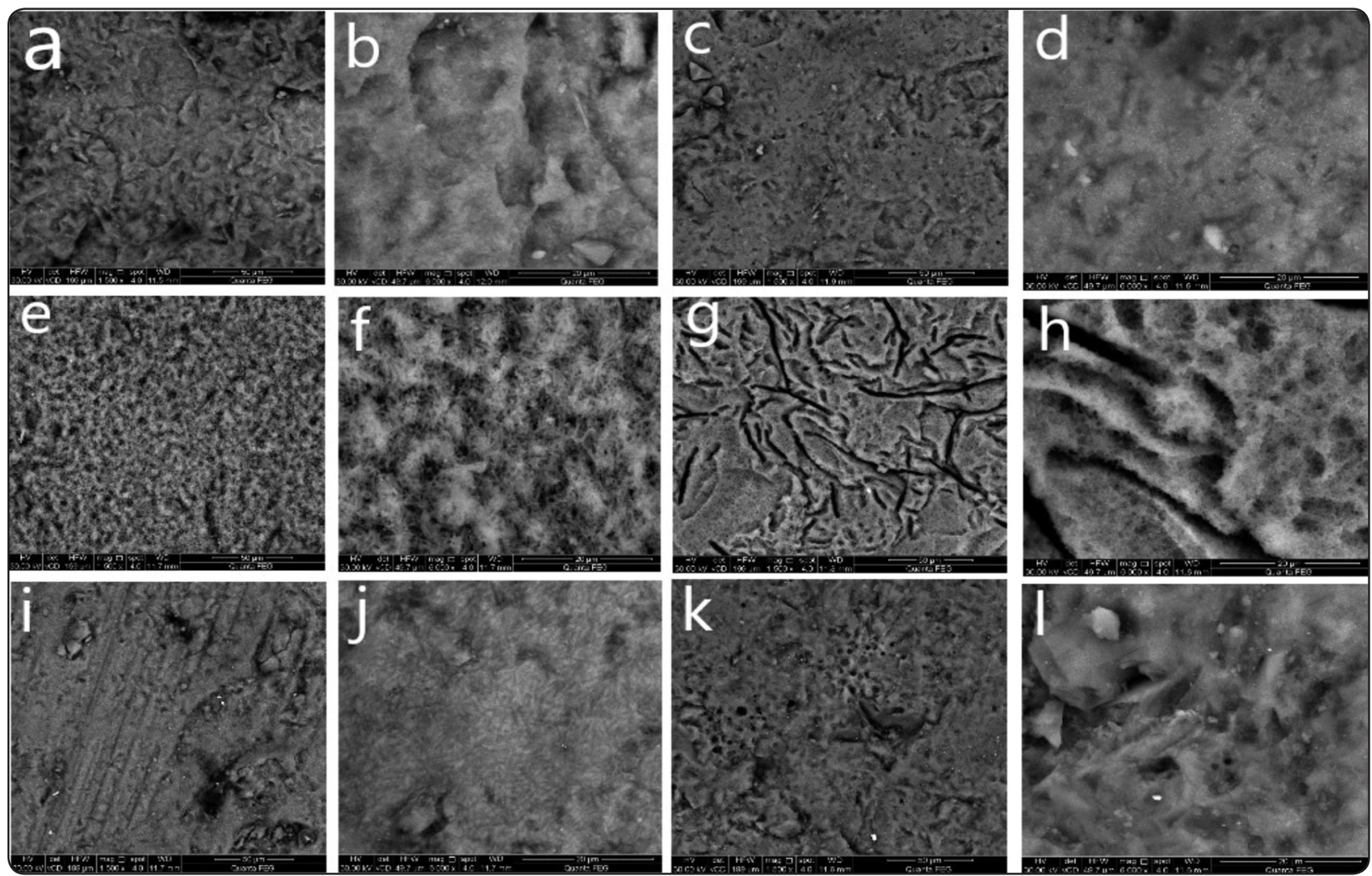

Fig. (2) SEM images of: a. IPS e.max Press before surface treatment showing thin long columnar crystals uniformly distributed in the glassy matrix (magnification 1500X), b. IPS e.max Press before surface treatment showing columnar crystals forming a uniform network (magnification 6000X), c. InitialTM LiSi Press before surface treatment showing platelet shaped fine crystals embedded in the matrix in the form of clusters or agglomerations, presence of furrows (magnification 1500X), d. -InitialTM LiSi Press before surface treatment showing nuclei at furrows, network of minute crystals, non-uniform matrix having agglomerates of crystals forming humps and valleys (magnification 6000X), e. IPS e.max Press after hydrofluoric acid etching surface treatment showing glassy matrix had been dissolved showing a uniform network of crystals distribution and uniform size of asecular crystals (magnification 1500X), f. IPS e.max Press after hydrofluoric acid etching surface treatment showing uniform distribution of elongated columnar crystals after glassy matrix dissolution (magnification $6000 X)$, g. InitialTM LiSi Press after hydrofluoric acid etching surface treatment showing dissolution of the glassy matrix at the furrows between the crystals' agglomerates forming deep furrows and dissolution of small amount of glassy matrix at the surface of the crystals agglomerations (magnification 1500X), h. InitialTM LiSi Press after hydrofluoric acid etching surface treatment showing the minute crystals at the furrows were removed and non-uniform distribution of the crystalline phase (magnification 6000X), i. IPS e.max Press after laser surface treatment showing presence of striations and cracks, melting of the surface, surface smoothness and non-uniform distribution of the crystalline phase (magnification 1500X), j. IPS e.max Press after laser surface treatment showing crystals growth, uniform surface smoothness and the crystals are masked by the glassy matrix (magnification 6000X), k. InitialTM LiSi Press after laser surface treatment showing Furrows are deepened, pores are formed, Smoother surface at the agglomerations and Less overall roughness than emax and formation of Cracks due to crystals growth (magnification 1500X), 1. InitialTM LiSi Press after laser surface treatment showing non-uniform surface topography, non-uniform roughness and crystals at the furrows are more clear and Growth of the crystals (magnification 6000X). 


\section{DISCUSSION}

Several surface treatment protocols to treat the intaglio surface of the ceramic restorations were reported ${ }^{[1,4,26,34,37]}$. Hydrofluoric acid etching protocol considered to be the gold standard protocol for treating the intaglio surface of the glass-ceramic restoration producing ceramic restorations with superior esthetics ${ }^{[26,38,39]}$.

By reviewing the literature, some studies ${ }^{[4,1,38,26]}$ evaluated the effect of Er:YAG laser (erbium yttrium aluminum garnet) on the surface roughness of lithium disilicate while fewer studies ${ }^{[24,7]}$ evaluated the effect of Er,Cr:YSGG laser (erbium, chromium: yttrium-scandium-gallium-garnet). Therefore, In the present study Er,Cr:YSGG laser was chosen to evaluate its effects on the surface roughness and topography of lithium disilicate.

The Er:YAG laser has been approved by the FDA (food and drug administration) in 1997, shortly after that, the Er,Cr:YSGG laser has been introduced ${ }^{[23,40]}$. Erbium lasers work through pulsed beam system, fibre delivery system and laser tip with water spray ${ }^{[7]}$. Both laser types have solid state crystals whether YAG (yttrium aluminium garnet) or YSGG (yttrium scandium gallium garnet) that are doped with erbium ions ${ }^{[41]}$. ER:YAG and Er,Cr:YSGG lasers are best absorbed by water and hydroxyl apatite which makes them capable of treating the soft and hard dental tissues ${ }^{[0,42]}$. Although both lasers have almost the same wavelength (ER:YAG: $2940 \mathrm{~nm}$ and the Er,Cr:YSGG: $2790 \mathrm{~nm}$ ), Er:YAG has higher affinity for water so it has higher absorption in water and lower penetration depth than Er,Cr:YSGG, so most of the laser ablation of Er:YAG occurs at the outer first layer ${ }^{[40-42]}$. Er,Cr:YSGG has three times more penetration depth than Er:YAG due to the difference in water absorption, so Er,Cr:YSGG needs longer time than Er:YAG to reach the ablation temperature to overcome the penetration depth and heat dissipation ${ }^{[40-42]}$. The Er,Cr:YSGG laser usually produces more thermal defects than Er:YAG laser due to the heat dissipation as it needs longer time to reach ablation than Er:YAG laser ${ }^{[40-42]}$.

In the present study, the results showed that there was no statistically significant difference between the mean Ra values of the two surface treatment protocols (acid etching and laser irradiation). Also, there was no significant difference in mean Ra values between the two ceramic types. Moreover there was a difference in the effect of both surface treatment protocols on the surface topography of the ceramic. So, the first and second proposed null hypotheses were accepted while the third null hypotheses was rejected.

For both ceramics whether at $0.5 \mathrm{~mm}$ or $1 \mathrm{~mm}$ thickness, the findings of the present study showed non-significant difference in the mean $\mathrm{Ra}$ values between the two surface treatment protocols. These results are in agreement with those reported by many studies ${ }^{[35,38]}$ revealing that both surface treatment protocols have the same Ra values for the treated ceramic surfaces. They claimed that both techniques act on the removal/dissolving of the glassy matrix and leaving the crystalline structure behind. With Hydrofluoric acid etching, the glassy matrix is dissolved and removed showing the elongated crystals of lithium disilicate, which creates irregularities, peaks and valleys through the high affinity of the fluoride present in the hydrofluoric acid to the silicon present in the lithium disilicate ceramic $^{[8,43]}$. On the other hand, laser irradiation treats the intaglio surface of the ceramic through the process of thermo-mechanical ablation. Ablation process of laser creates micro-roughness by dissolving the glassy matrix of the ceramics which increases the micro-mechanical retention ${ }^{[3,44]}$. These investigations were verified by the SEM analysis. The SEM images of both ceramics treated with hydrofluoric acid revealed removal of the glassy matrix and formation of a uniform network of crystalline structure, while for ceramic surfaces treated with laser irradiation, SEM images showed 
dissolving of the glassy matrix and formation of micro-roughness. (Figures 1e, 1f, $1 \mathrm{~g} \& 1 \mathrm{~h}$ ).

On the contrary, these findings disagreed with those reported by Vohra et al ${ }^{[24]}$. They found that ceramic surfaces treated by Er,Cr:YSGG laser has more surface roughness than those treated by hydrofluoric acid etching. The variation in the results may be attributed to differences in research methodology as they used SEM analysis for surface roughness measurement, compared to the surface profilometry used in the present study. The contact stylus profilometer provides accuracy, reliability and standardization compared to other surface roughness measuring methods ${ }^{[45]}$. Moreover, the Er,Cr:YSGG laser parameters used were different as they used higher energy output (7W) and 4 minutes exposure time in their study, which was longer than the exposure time (60 seconds) in the present study. Moreover, some of their groups had double laser exposures. Gökçe et al ${ }^{[46]}$ and Albaker et al ${ }^{[47]}$ reported that higher power settings and higher exposure time may cause over-destruction of the crystalline structure and/or the glassy matrix and increase the surface roughness.

The non-significant difference in the mean $\mathrm{Ra}$ values between untreated IPS e.max Press and GC Initial ${ }^{\mathrm{TM}} \mathrm{LiSi}$ Press specimens' surfaces, whether with $0.5 \mathrm{~mm}$ or $1 \mathrm{~mm}$ thickness could be attributed to the similarity between the two ceramics in the volume ratio of crystalline phase to the glassy matrix (70\% by volume); despite the difference in the crystals' size of both ceramics. Also, both ceramics have a comparable glassy matrix proportions ${ }^{[48]}$. Beside, the disc specimens of both ceramics passed through the same standardized steps during construction and the wax disc patterns were sliced using an isomet, which provides standardized surface roughness. This result is verified by SEM analysis. The SEM images of the two ceramics showed almost the same surface roughness. (Figures 1a, 1b, 1c \& 1d).
The SEM images of the present study showed that GC Initial ${ }^{\mathrm{TM}}$ LiSi Press specimens have smaller sized lithium disilicate crystals, which are equally dispersed on the glassy matrix than those of IPS e.max Press. (Figures 1a, 1b, 1c \& 1d), this came in accord with Ohashi et al ${ }^{[48]}$ and Hallman et al ${ }^{[49]}$ who reported that GC Initial ${ }^{\mathrm{TM}} \mathrm{LiSi}$ Press is a new lithium disilicate pressable ceramic manufactured by GC Corporation (Tokyo, Japan) with HDM technology (high density micronization) that provides equal dispersion of the lithium disilicate micro-crystals throughout the entire glassy matrix rather than the random dispersion of the larger size crystals of IPS e.max Press in the glass matrix.

The SEM images of the present study found that the two mechanisms revealed difference in the surface topography (Figures: 1e, 1f, 1g, 1h, 1i, 1j, $1 \mathrm{k} \& 11)$. Laser irradiated surfaces showed more waviness than those of hydrofluoric acid etched surfaces. Moreover, the SEM Images showed that the ceramic specimens treated by Er,Cr:YSGG laser had areas of defects or cracks and showed an increase in the size of the crystals. (Figures: 1i, $1 \mathrm{j}, 1 \mathrm{k} \& 11)$. These findings came in accord with Kursoglu et al ${ }^{[7]}$ who reported that the thermal effect of Er,Cr:YSGG laser through heat dissipation may have led to melting of the ceramic surface which produced more waviness on the surface topography. Also, that thermal effect caused surface defects and cracks in the ceramic. According to Albaker et al ${ }^{[47]}$, lithium disilicate ceramics treated with Er,Cr:YSGG laser showed less bond integrity than those treated with hydrofluoric acid etching due to the structural and topographical changes caused by Er,Cr:YSGG laser.

As Er,Cr:YSGG laser ceramic etching is a new surface treatment protocol, future clinical studies are necessary to evaluate its effect with different parameters on lithium disilicate ceramic restorations in-service under oral environmental variations. 


\section{CONCLUSION}

Within the parameters used and the limitations of this study, the following could be concluded:

1. Hydrofluoric acid etching and Er,Cr:YSGG laser surface treatment protocols produced comparable surface roughness on the lithium disilicate ceramics.

2. Er,Cr:YSGG laser surface treatment protocol had a negative effect on the surface topography of lithium disilicate ceramics.

3. Despite the difference in microstructure, GC Initial $^{\mathrm{TM}}$ LiSi Press and IPS e.max Press had comparable surface roughness.

\section{REFERENCES}

1. Turgut S, Bagis B, Ayaz EA, Korkmaz FM, Ulusoy KU, Bagis YH. How will surface treatments affect the translucency of porcelain laminate veneers? J Adv Prosthodont. 2014;6(1):8-13.

2. Willard A, Gabriel Chu TM. The science and application of IPS e.Max dental ceramic. Kaohsiung J Med Sci. 2018;34(4):238-42.

3. Kirmali O, Kustarci A, Kapdan A. Surface roughness and morphologic changes of zirconia: Effect of different surface treatment. Niger J Clin Pract. 2015;18(1):124-9.

4. Turgut S, Bağiş B, Korkmaz FM, Tamam E. Do surface treatments affect the optical properties of ceramic veneers? J Prosthet Dent. 2014;112(3):618-24.

5. Prochnow C, Venturini AB, Grasel R, Bottino MC, Valandro LF. Effect of etching with distinct hydrofluoric acid concentrations on the flexural strength of a lithium disilicate-based glass ceramic. J Biomed Mater Res - Part B Appl Biomater. 2017;105(4):885-91.

6. Peumans M, Van Meerbeek B, Lambrechts P, Vanherle G. Porcelain veneers: a review of the literature. J Dent. 2000;28(3):163-77.

7. Kursoglu P, Yurdaguven H, Kazazoglu E, Çalýkkocaoglu S, Gursoy T. Effect of Er,Cr:YSGG laser on ceramic surface. Balk J Stomatol. 2006;10:103-9.

8. Sundfeld D, Palialol ARM, Fugolin APP. The effect of hydrofluoric acid and resin cement formulation on the bond strength to lithium disilicate ceramic. Braz Oral Res. 2018;32:e43.
9. Science M, Dilber E. Effect of different surface treatments on roughness of IPS Empress 2 ceramic Effect of different surface treatments on roughness of IPS Empress 2 ceramic. Lasers Med Sci. 2012;27(2):267-72.

10. Addison O, Marquis PM, Fleming GJP. The impact of hydrofluoric acid surface treatments on the performance of a porcelain laminate restorative material. Dent Mater. 2007;23(4):461-8

11. Erdemir U, Sancakli HS, Sancakli E. Shear bond strength of a new self-adhering flowable composite resin for lithium disilicatereinforced CAD/CAM ceramic material. J Adv Prosthodont. 2014;6(6):434-43.

12. Bruzi G, Carvalho AO, Giannini M, Maia HP, Magne P. Post-etching cleaning influences the resin shear bond strength to CAD/CAM lithium-disilicate ceramics. Appl Adhes Sci. 2017;5(1):17.

13. Lucas Z, Alvaro D, Estevao T, John F. Effect of hydrofluoric acid etching duration on the roughness and flexural strength of a lithium disilicate-based glass ceramic. Braz Dent J. 2011;22(1):45-50.

14. Hooshmand T, Parvizi S, Keshvad A. Effect of surface acid etching on the biaxial flexural strength of two hotpressed glass ceramics. J Prosthodont. 2008;5:415-9.

15. Xiaoping L, Dongfeng R, Silikas N. Effect of etching time and resin bond on the flexural strength of IPS e.max Press glass ceramic. Dent Mater. 2014;30(12):330-6.

16. Liu L, Liu S, Song X, Zhu Q, Zhang W. Effect of Nd: YAG laser irradiation on surface properties and bond strength of zirconia ceramics. Lasers Med Sci. 2015;30(2):627-34.

17. Erdur EA, Basciftci FA. Effect of Ti:sapphire laser on shear bond strength of orthodontic brackets to ceramic surfaces. Lasers Surg Med. 2015; 47(6):512-9.

18. Alakuş Sabuncuoğlu F, Ertürk E. The Effect of Different Surface Treatment Techniques on The Surface Roughness of Feldspathic Porcelain. J Istanbul Univ Fac Dent. 2016;50(3):1-7.

19. Barutcigil K, Barutcigil Ç, Kul E, Özarslan MM, Buyukkaplan US. Effect of Different Surface Treatments on Bond Strength of Resin Cement to a CAD/CAM Restorative Material. J Prosthodont. 2019;28(1):71-78.

20. Sari T, Tuncel I, Usumez A, Gutknecht N. Transmission of Er:YAG laser through different dental ceramics. Photomed Laser Surg. 2014; 32(1):37-41. 
21. Mirhashemi AH, Hossaini SMH, Etemadi A, Kharazifard MJ, Bahador A, Soudi A. Effect of Er:YAG and Er,Cr:YSGG Lasers on Ceramic Bracket Debonding from Composite Blocks. Front Dent. 2019;16(2):88-95.

22. Topcuoglu T, Oksayan R, Topcuoglu S, Coskun ME, Isman NE. Effect of er:yag laser pulse duration on shear bond strength of metal brackets bonded to a porcelain surface. Photomed Laser Surg. 2013;31(6):240-6

23. De Paula Eduardo C, Bello-Silva MS, Moretto SG, Cesar PF, De Freitas PM. Microtensile bond strength of composite resin to glass-infiltrated alumina composite conditioned with Er,Cr:YSGG laser. Lasers Med Sci. 2012; 27:7-14..

24. Vohra F, Labban N, Al-Hussaini A. Influence of Er;Cr:YSGG Laser on Shear Bond Strength and Color Stability of Lithium Disilicate Ceramics: An In Vitro Study . Photobiomodulation, Photomedicine, Laser Surg. 2019;37(8):483-8.

25. Alkhudhairy F, Naseem M, Bin-Shuwaish M, Vohra F. Efficacy of Er Cr: YSGG laser therapy at different frequency and power levels on bond integrity of composite to bleached enamel. Photodiagnosis Photodyn Ther. 2018;22:34-8.

26. Kursoglu P, Motro PFK, Yurdaguven H. Shear bond strength of resin cement to an acid etched and a laser irradiated ceramic surface. J Adv Prosthodont. 2013;5(2):98-103

27. M. Özcan, A. Allahbeickaraghi, and M. Dündar, "Possible hazardous effects of hydrofluoric acid and recommendations for treatment approach: A review," Clin. Oral Investig. 2012;16(1):15-23.

28. B. J. Dunn, MacKinnon, Michael A, Knowlden, Norman F, Billmaier, Donald J. "Hydrofluoric acid dermal burns: An assessment of treatment efficacy using an experimental pig model,” J. Occup. Med., 1992; 902-9

29. M. Gallerani, V. Bettoli, L. Peron, and R. Manfredini, "Systemic and topical effects of intradermal hydrofluoric acid,” Am. J. Emerg. Med., 1998;16(5):521-2

30. A. Pathak, H. Nandan, R. Sthapak, S. Sharma, and M. Dubey, "Comparative assessment of hydrofluoric acid and sandblasting etching technique on porcelain crowns," Asian Pacific J. Heal. Sci., 2019; 6(2):175-81

31. T. Sriamporn, P. Kraisintu, L. P. See, S. Swasdison, A. Klaisiri, and N. Thamrongananskul, "Effect of Different Neutralizing Agents on Feldspathic Porcelain Etched by Hydrofluoric Acid,” Eur. J. Dent., 2019;13(1):75-81.
32. S. Miersch, A. König, S. Mehlhorn, F. Fuchs, S. Hahnel, and A. Rauch, "Adhesive luting of orthodontic devices to silica-based ceramic crowns - comparison of shear bond strength and surface properties," Clin. Oral Investig., 2020;24:3009-16

33. Jaiane Bandoli Monteiroa, Marcelo Gallo Oliania, Luis Felipe Guilardib, Catina Prochnowb. "Fatigue failure load of zirconia-reinforced lithium silicate glass ceramic cemented to a dentin analogue: Effect of etching time and hydrofluoric acid concentration," J. Mech. Behav. Biomed. Mater., 2018; (77):375-82.

34. H. B. Kara, E. Dilber, O. Koc, A. N. Ozturk, and M. Bulbul, "Effect of different surface treatments on roughness of IPS Empress 2 ceramic," Lasers Med. Sci., 2012;27(2):267-72.

35. Dilber E, Yavuz T, Kara HB, Ozturk AN. Comparison of the effects of surface treatments on roughness of two ceramic systems. Photomed Laser Surg. 2012;30(6):308-14.

36. S. Taşın, G. Celik, A. İsmatullaev, and A. Usumez, "The effect of artificial accelerated aging on the color stability, microhardness, and surface roughness of different dental laminate veneer materials," J. Esthet. Restor. Dent., 2020:1-7.

37. Addison O, Marquis PM, Fleming GJP. Adhesive luting of all-ceramic restorations--the impact of cementation variables and short-term water storage on the strength of a feldspathic dental ceramic. J Adhes Dent. 2008;10: 285-93.

38. Yavuz T, Dilber E, Kara HB, Tuncdemir AR, Ozturk AN Effects of different surface treatments on shear bond strength in two different ceramic systems. Lasers Med Sci. 2013;28(5):1233-9.

39. Saracoglu A, Cura C, Cotert HS. Effect of various surface treatment methods on the bond strength of the heatpressed ceramic samples. J Oral Rehabil. 2004;31:790-7.

40. Van As G. Erbium lasers in dentistry. Dent Clin North Am. 2004;48(4):1017-1059.

41. Diaci J, Gaspirc B. REVIEW. Comparison of Er : YAG and $\mathrm{Er}, \mathrm{Cr}$ : YSGG lasers used in dentistry Comparison of $\mathrm{Er}$ : YAG and $\mathrm{Er}, \mathrm{Cr}$ : YSGG lasers used in dentistry. $\mathrm{J}$ Laser Heal Acad. 2012;2012(1):1-13.

42. Mirhashemi A, Sharifi N, Moharrami M, Chiniforush N Evaluation of different types of lasers in surface conditioning of porcelains: A review article. J Lasers Med Sci. 2017;8(3):101-11. 


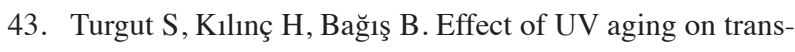
lucency of currently used esthetic CAD-CAM materials. J Esthet Restor Dent. 2019;31(2):147-152.

44. Turp V, Akgungor G, Sen D, Tuncelli B. Evaluation of surface topography of zirconia ceramic after Er:YAG laser etching. Photomed Laser Surg. 2014;32(10):533-9.

45. Whitehead SA, Shearer AC, Watts DC, Wilson NHF. Comparison of methods for measuring surface roughness of ceramic. J Oral Rehabil. 1995;22(6):421-7.

46. Gökçe B, Özpinar B, Dündar M, Çömlekoglu E, Sen BH, Güngor MA. Bond strengths of all-ceramics: Acid vs laser etching. Oper Dent. 2007;32(2):173-8.
47. Albaker AM, Al Deeb L, Alhenaki AM. Bonding integrity and compressive strength of re-bonded, surface conditioned and Er Cr YSGG laser treated lithium disilicate ceramics. J Appl Biomater Funct Mater. 2020;18:1-7.

48. Ohashi K, Kameyama Y, Wada Y. Evaluation and comparison of the characteristics of three pressable lithium disilicate glass ceramic materials. Int J Dev Res. 2017;7(11):16711-16.

49. Hallmann L, Ulmer P, Gerngross MD. Properties of hot-pressed lithium silicate glass-ceramics. Dent Mater. 2019;35(5):713-29. 